\title{
Identification of aberrantly expressed glycans in gastric cancer by integrated lectin microarray and mass spectrometric analyses
}

\author{
Xiang Li ${ }^{1,2}$, Feng Guan ${ }^{2,3}$, Dongliang $\mathrm{Li}^{3,4}$, Zengqi Tan ${ }^{3}$, Ganglong Yang ${ }^{3}$, Yanli Wu ${ }^{3}$, \\ Zhaohui Huang ${ }^{1}$ \\ ${ }^{1}$ Wuxi Oncology Institute, Affiliated Hospital of Jiangnan University, Wuxi, Jiangsu, China \\ ${ }^{2}$ College of Life Science, Northwest University, Xi'an, Shannxi, China \\ ${ }^{3}$ The Key Laboratory of Carbohydrate Chemistry \& Biotechnology, Ministry of Education, School of Biotechnology, Jiangnan \\ University, Wuxi, China \\ ${ }^{4}$ Bioimaging Core, Faculty of Health Sciences, University of Macau, Taipa, Macau SAR, China \\ Correspondence to: Zhaohui Huang, email: hzhwxsy@126.com
}

Keywords: gastric cancer, lectin microarray, lectin histochemistry, mass spectrometry, N-glycan

Received: May 12,2016 Accepted: November 01, $2016 \quad$ Published: November 24, 2016

\section{ABSTRACT}

Cancer progression is usually associated with alterations of glycan expression patterns. Little is known regarding global glycomics in gastric cancer, the most common type of epithelial cancer. We integrated lectin microarray and mass spectrometry (MS) methods to profile glycan expression in three gastric cancer cell lines (SGC-7901, HGC-27, and MGC-803) and one normal gastric epithelial cell line (GES-1). Significantly altered glycans were confirmed by lectin staining and MALDITOF/TOF-MS. The three cancer cell lines showed increased levels of core-fucosylated N-glycans, GalNAca-Ser/Thr (Tn antigen), and Sia2-6Galß1-4GIcNAc N-glycans, but reduced levels of biantennary N-glycans, Galß1-3GalNAca-Ser/Thr ( $\mathrm{T}$ antigen), and $($ GICNAC) $n$ N-glycans. Lectin histochemistry was used to validate aberrant expression of four representative glycans (core-fucosylation, Sia2-6Galß1-4GIcNAC, biantennary $\mathrm{N}$-glycans, $\mathrm{T}$ antigen, recognized respectively by lectins LCA, SNA, PHA-E+L, and ACA) in clinical gastric cancer samples. Lower binding capacity for ACA was correlated with significantly poorer patient prognosis. Our findings indicate for the first time that glycans recognized by LCA, ACA, and PHA-E $+L$ are aberrantly expressed in gastric cancer, and suggest that ACA is a potential prognostic factor for gastric cancer.

\section{INTRODUCTION}

Gastric cancer is a common epithelial cancer and the second leading cause of cancer death worldwide $[1,2]$. In China, 400,000 new cases of gastric cancer and $\sim 300,000$ deaths from the disease were reported during 2005-2010, making it the second most common type of cancer $[3,4]$. New prognostic biomarkers are needed to facilitate early diagnosis of cancer, improve treatment outcome, and prolong patient survival. Early detection of gastric cancer typically relies on endoscopic examination, and diagnostic accuracy depends on the skill of the endoscopist [5]. More reliable tissue or serum biomarkers for early diagnosis of gastric cancer are highly desirable.

Glycosylation is a common post-translational modification estimated to occur in $>70 \%$ of human proteins [6]. It plays crucial roles in molecular recognition, cell-cell adhesion, molecular trafficking, receptor activation, signal transduction, and endocytosis [7]. Aberrant protein glycosylation often occurs during malignant transformation, leads to formation of specific tumor-associated glycans, and is associated with tumor invasiveness, metastasis, and overall poor prognosis $[8,9]$.

Several studies have suggested aberrant expression of glycans in gastric cancer cells. Serum levels of sialyl Lewis $^{\mathrm{x}}$, sialyl Lewis ${ }^{\mathrm{a}}$, and sialyl-Tn antigens were elevated in gastric cancer patients [10]. Ishizuka et al found that complex type N-glycans were accumulated in gastric cancer cell lines MKN7 and MKN45 [11]. Huang et al [12] proposed that two lectins (VVA and MPL) are potential biomarkers for distinguishing gastric cancer from gastric ulcer. However, to date glycans have not been extensively applied as clinical tumor biomarkers because of (i) technical difficulties in glycan purification and analysis, 
and (ii) variations in accuracy depending on the analytical method and type of equipment [13]. An integrated strategy is needed for identification of aberrantly expressed glycans in gastric cancer.

In the present study, we used an approach integrating lectin microarray and mass spectrometry (MS) to quantitatively analyze glycan expression in gastric cancer cells and normal gastric epithelial cells, and confirmed our results in clinical gastric cancer tissues and their adjacent noncancerous tissues. Our findings indicate that (i) core-fucosylation, biantennary N-glycans, and Gal $\beta 1$ 3 GalNAc $\alpha-S e r / T h r$ (T antigen), recognized respectively by the lectins LCA, PHA-E+L, and ACA, are aberrantly expressed in gastric cancer, and (ii) ACA is a potential prognostic tool for gastric cancer.

\section{RESULTS}

\section{Glycopattern analysis of normal gastric and gastric cancer cell lines}

Patterns of glycoproteins reflect the expression, function, and metabolism of oligosaccharides in cells. We used lectin microarrays containing 37 lectins
(Supplementary Table S2), two negative controls (BSA), and one positive control (Cy3-BSA) (Supplementary Figure S1) to analyze fine glycan structures of glycoproteins in GES-1, SGC-7901, HGC-27, and MGC-803 cells. Significant differences (fold change $>1.5$ observed in at least two gastric cancer cell lines) of glycans recognized by 10 different lectins were observed for cancer cells in comparison with normal cells (Figure 1). Gastric cancer cells had higher expression of five glycan structures recognized by lectins HHL, LCA, NPA, VVA, and SNA, and lower expression of five glycan structures recognized by SBA, PWM, ACA, WGA, and PHA-E+L (Table 1).

Increased staining by SNA (recognizing Sia26Gal $\beta 1-4 G l c N A c)$, LCA (recognizing Fuc $\alpha 1-6$ GlcNAc), VVA (recognizing GalNAc $\alpha-S e r / T h r$ (Tn antigen)) indicated elevated levels of $\alpha 2-6$ sialylation, corefucosylation, and Tn antigen in MGC-803, HGC-27, and SGC-7901 cells, respectively. Fluorescence intensity of HHL and NPA (recognizing non-substituted $\alpha 1-3$ and a1-6Man) was also higher in these gastric cancer cell lines, suggesting increased expression of high-mannosetype N-glycans. Reduced fluorescence intensity of PHA-E $+\mathrm{L}$ and ACA indicated down-regulation of triand tetra-antennary structures and Gal $\beta 1-3$ GalNAc $\alpha-$
GES-1

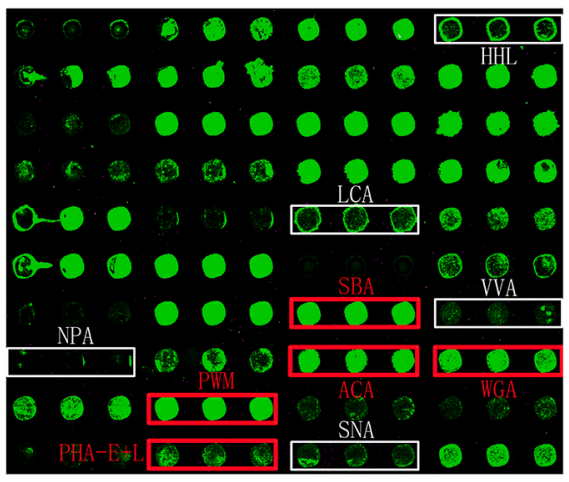

HGC 27

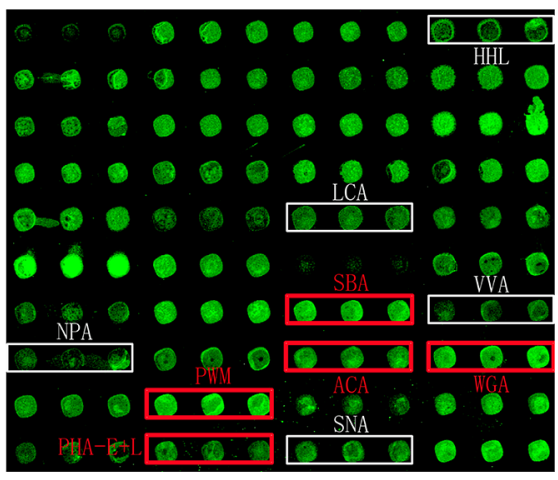

MGC-803

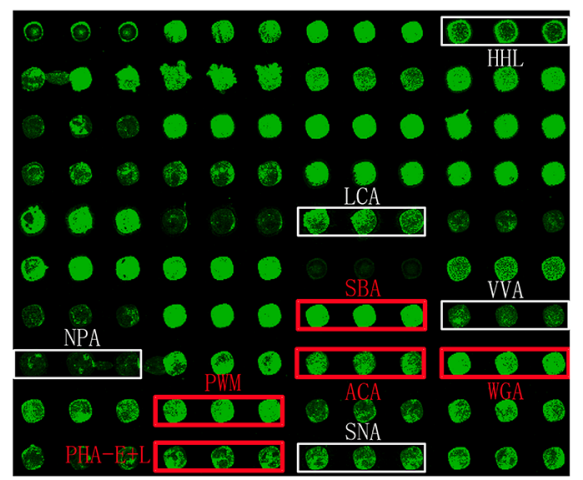

SGC-7901

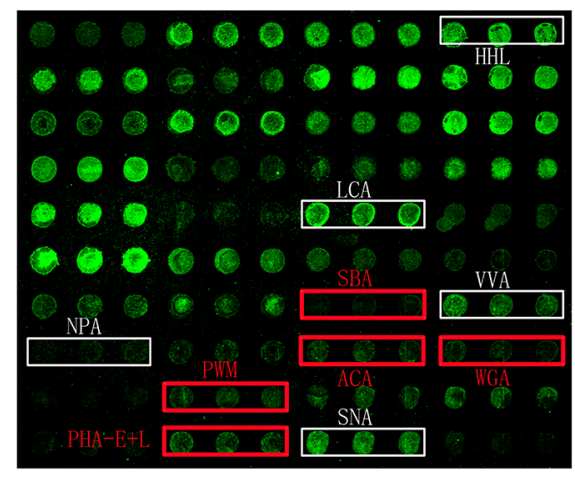

Figure 1: Glycan profiles of gastric cancer and normal gastric cell lines obtained by lectin microarray analysis. Differentially expressed glycans in three gastric cancer cell lines (SGC-7901, HGC-27, and MGC-803) and one normal gastric epithelial cell line (GES-1). White boxes: fluorescence intensities of lectins higher in gastric cancer cells. Red boxes: fluorescence intensities of lectins lower in gastric cancer cells. Each sample was observed consistently by three repeated slides. One representative slide was shown. 
Table 1: Differential glycopatterns of four cell lines (three gastric cancer and one normal gastric epithelia), determined by lectin microarray analysis

\begin{tabular}{|c|c|c|c|c|c|}
\hline & $\begin{array}{l}\text { MGC-803/ } \\
\text { GES-1 }\end{array}$ & $\begin{array}{c}\text { HGC-27/ } \\
\text { GES-1 }\end{array}$ & $\begin{array}{l}\text { SGC-7901/ } \\
\text { GES-1 }\end{array}$ & & \\
\hline HHL & 1.131 & 1.707 & 1.904 & Non-substituted $\alpha 1-6 \mathrm{Man}$ & \\
\hline LCA & 1.007 & 1.532 & 1.915 & Fuc $\alpha 1-6$ GlcNAc (core) & \\
\hline SNA & 0.613 & 1.567 & 1.839 & Sia2-6Galß1-4GlcNAc & \\
\hline VVA & 1.134 & 1.610 & 1.583 & GalNAc $\alpha-S e r / T h r(T n)$ & Thr \\
\hline NPA & 1.424 & 1.695 & 1.099 & Non-substituted $\alpha 1-6 \mathrm{Man}$ & \\
\hline SBA & 0.966 & 0.758 & 0.445 & $\begin{array}{c}\text { Terminal GalNAc (especially } \\
\text { GalNAc } 1-3 \mathrm{Gal} \text { ) }\end{array}$ & \\
\hline $\begin{array}{l}\text { PHA- } \\
\text { E+L }\end{array}$ & 1.096 & 0.610 & 1.054 & Biantennary N-glycans & \\
\hline WGA & 1.101 & 0.885 & 0.699 & $(\text { GlcNAc })_{n}$ & \\
\hline PWM & 0.941 & 0.770 & 0.616 & GlcNAc & \\
\hline ACA & 0.896 & 0.596 & 0.730 & Gal $\beta 1-3$ GalNAc $\alpha-S e r / T h r$ & $\mathrm{Oin} \square$-serrmr \\
\hline
\end{tabular}

Ser/Thr structure, and reduced SBA, WGA, and PWM fluorescence intensity indicated lower expression of terminal GalNAc and GlcNAc, in gastric cancer cells (Figure 1B; Table 1).

Because the glycans recognized by ACA, PHA$\mathrm{E}+\mathrm{L}, \mathrm{LCA}$, and SNA are known to be aberrantly expressed in several types of cancer, we selected these four lectins for the validation of differentially expressed glycans in our experimental cell lines. The three gastric cancer cell lines showed higher fluorescence signal intensities of LCA and SNA but lower intensities of PHA-E+L and ACA, consistent with the results of lectin microarray analysis (Figure 2).

\section{N-Glycan profiles obtained by matrix-assisted laser desorption/ ionization time-of-flight mass spectrometry (MALDI-TOF/TOF-MS)}

N-Glycans are involved in cell-cell and cell-matrix interactions, receptor-mediated functions, and specific protein functions [14, 15]. Aberrant N-glycosylation patterns have been observed in many types of tumors, suggesting the potential use of cancer-associated N-glycans as tumor biomarkers [16-18]. We used MALDI-TOF/
TOF-MS to profile total N-glycans in GES-1, SGC-7901, HGC-27, and MGC-803 cells and observed abnormal $\mathrm{N}$-glycosylation of gastric cancer.

Representative MALDI-TOF/TOF-MS spectra of $\mathrm{N}$-glycans with signal-to-noise ratios $>3$ from total glycoproteins were annotated using the GlycoWorkbench software program (Figure 3). GES-1, SGC-7901, HGC27, and MGC-803 cells showed 9, 22, 18, and 10 distinct $\mathrm{m} / \mathrm{z} \mathrm{N}$-glycans in both two independent experiments, respectively. Nine $\mathrm{N}$-glycan structures were present in all four cell lines. SGC-7901 and HGC-27 cells had ten and four unique $\mathrm{N}$-glycan structures, respectively (Table 2). MALDI-TOF/TOF-MS analysis per se is not sufficient to yield detailed glycan composition. Therefore, MALDI-TOF/TOF-MS was further performed to obtain detailed information regarding substitutions and branching patterns of monosaccharide constituents. Tandem MS spectra of precursor ions with $\mathrm{m} / \mathrm{z} 1743.613$, 1809.639, 1905.634, and 2174.772 are shown in Figure 4. Structures of mannose branches were revealed by fragment ions $\mathrm{B}_{4} \mathrm{Y}_{3 \beta}(833.253)$ and $\mathrm{B}_{4} \mathrm{Y}_{5 \beta}(1157.437)$ in $\mathrm{m} / \mathrm{z}$ 1743.613. The presence of fucose was indicated by $\mathrm{B}_{4} \mathrm{Y}_{6 \beta}(1239.41)$ in $\mathrm{m} / \mathrm{z} 1809.639$ and by $\mathrm{Y}_{1}(2028.714)$ in $\mathrm{m} / \mathrm{z} 2174.772$. 
Relative variation of major types of N-glycans in the four cell lines is summarized in Table 3. The percentage of high-mannose-type N-glycan structures was greater $(93.0 \%)$ in GES-1 than in SGC-7901 (54.8\%) or HGC-27 (70.5\%). In contrast, complex-type N-glycan structures had a lower percentage in GES-1 (7.0\%) than in SGC-7901 (45.2\%) or HGC-27 (29.5\%). Bi-, tri-, tetra-, and penta-antennary $\mathrm{N}$-glycan structures (particularly triantennary) were suppressed in GES-1. Percentages of fucosylated complex-type $\mathrm{N}$-glycan structures were higher in SGC-7901 (37.9\%) and HGC-27 (21.3\%) than in GES$1(7.0 \%)$. The role of sialylated $\mathrm{N}$-glycans in gastric cancer was investigated using acetohydrazide, which modifies both $\alpha 2-3$-linked and $\alpha 2-6$-linked sialic acids. Sialylated $\mathrm{N}$-glycans were then annotated using the GlycoWorkbench program (Figure 3; sialic acid residues labeled as "Ah").

\section{O-Glycan profiles obtained by MALDI-TOF-MS}

Representative MALDI-TOF-MS spectra of O-glycans with signal-to-noise ratios $>4$ from total glycoproteins were also annotated using GlycoWorkbench software program. A total of $36 \mathrm{O}$-glycan structures were identified in the four cell lines, 22 in GES-1, 21 in SGC7901, 25 in HGC-27, and 29 in MGC-803 (Figure 5 and Table 4). A total of $12 \mathrm{O}$-glycans were presented in all the four cells. Two O-glycans with m/z 1247.986 ((Glc NAc $\left.)_{3}(\mathrm{Gal})_{1}(\mathrm{GalNAc})_{1}\right)$ and $1606.830\left((\mathrm{Fuc})_{1}(\mathrm{GlcNAc})_{2}\right.$ $\left.(\mathrm{Gal})_{3}(\mathrm{GalNAc})_{1}\right)$ were specifically identified in SGC7901, HGC-27, and MGC-803. One O-glycans with $\mathrm{m} / \mathrm{z}$ $1614.859\left((\mathrm{GlcNAc})_{1}(\mathrm{Gal})_{4}(\mathrm{GalNAc})_{2}\right)$ was specifically identified in GES-1. Interestingly, the relative intensity of Thomsen-Friedenreich antigen (TF antigen or $\mathrm{T}$ antigen) with $\mathrm{m} / \mathrm{z} 512.307$ (Gal( $\beta 1-3)$ GalNAc) was greater $(18.69 \%)$ in GES-1 than in HGC-27 $(5.53 \%)$ or MGC$803(6.80 \%)$, and slightly higher in GES-1 than SGC-7901 (17.99\%) (Table 4).

\section{Validation of differential glycopatterns in clinical gastric cancer tissues by lectin histochemistry}

Expression levels of LCA, SNA, ACA, and PHA-E+L in gastric cancer cells were significantly different from those in normal gastric epithelial cells. We examined the expression of the glycans recognized by these four lectins in clinical gastric cancer tissues and adjacent non-cancerous tissues
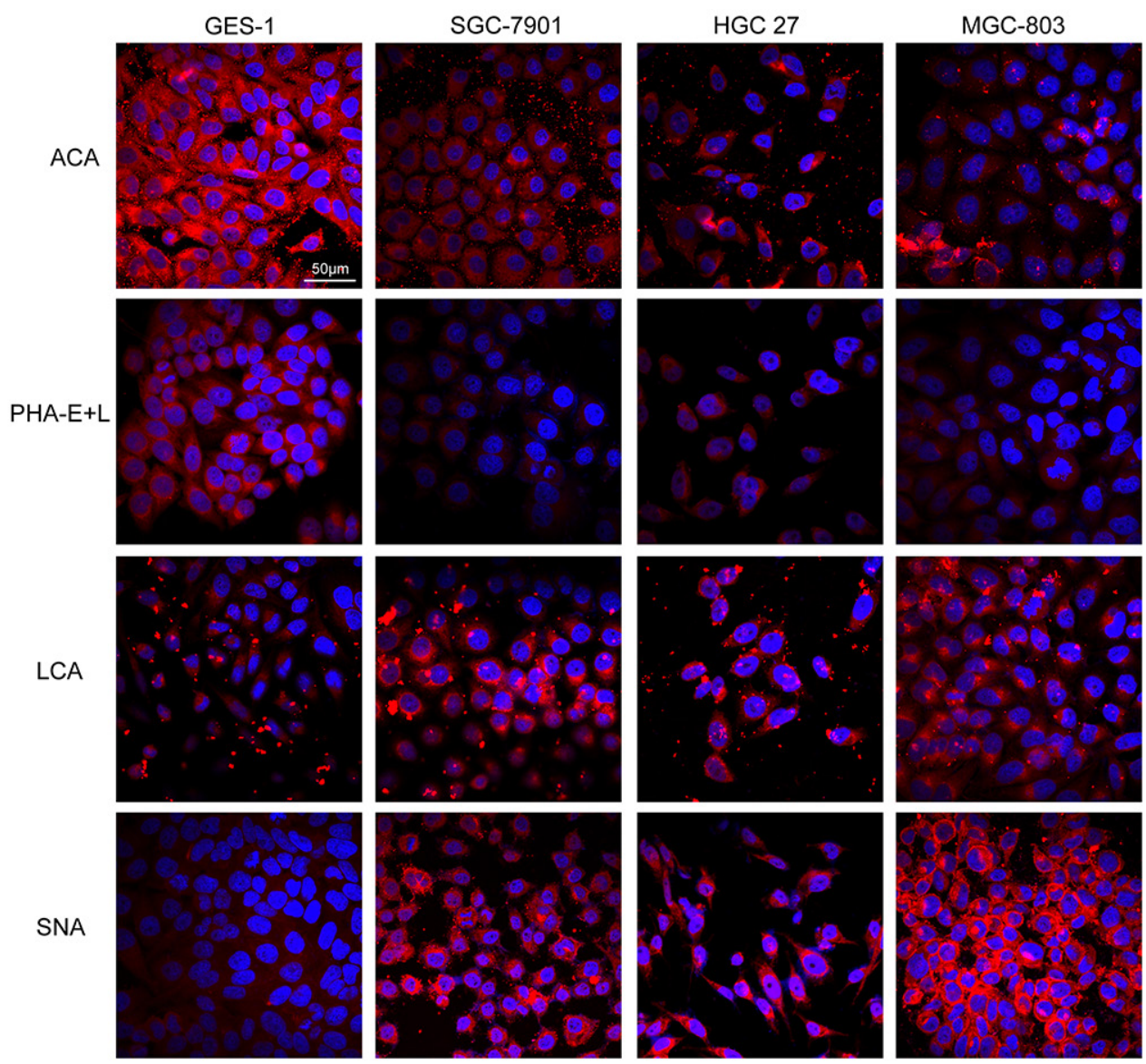

Figure 2: Expression of glycans in the four cell lines evaluated by lectin staining. GES-1, SGC-7901, HGC-27, and MGC803cells were stained with Cy3-labeled lectins (ACA, PHA-E+L, LCA, SNA). Signals in merge images of Cy3-conjugated lectins and DAPI staining of nuclei are shown. Objective magnification: 60x. 
(Figure 6A). Aberrant expression of the glycans recognized by LCA, PHA-E+L, and ACA was consistent with findings for gastric cancer cell lines (Figure 6B). In contrast, binding of SNA to clinical gastric cancer tissues vs. adjacent noncancerous tissues was not significantly different (Figure 6B).

To further evaluate the potential clinical value of these glycan structures in gastric cancer prognosis, patients were classified into "relatively high" and "relatively low" groups using the median level of each lectin in tumor tissues as a cutoff value. Notably, reduced
ACA binding in gastric cancer was significantly correlated with higher TNM stage $(r=-0.204, P=0.026)$ and poorer prognosis $(P=0.008)$ (Figure 7$)$. After adjusting for age, gender, $\mathrm{T}$ stage, $\mathrm{N}$ stage, TNM stage and tumor grade, Cox multivariate analyses showed that ACA expression is an independent prognostic factor for gastric cancer $(\mathrm{HR}=0.355 ; 95 \% \mathrm{CI}=0.198-0.636, P=0.001)$. No significant associations were observed between binding capacities of the other three lectins (LCA, SNA, PHA$\mathrm{E}+\mathrm{L})$ and clinicopathologic features of gastric cancer.

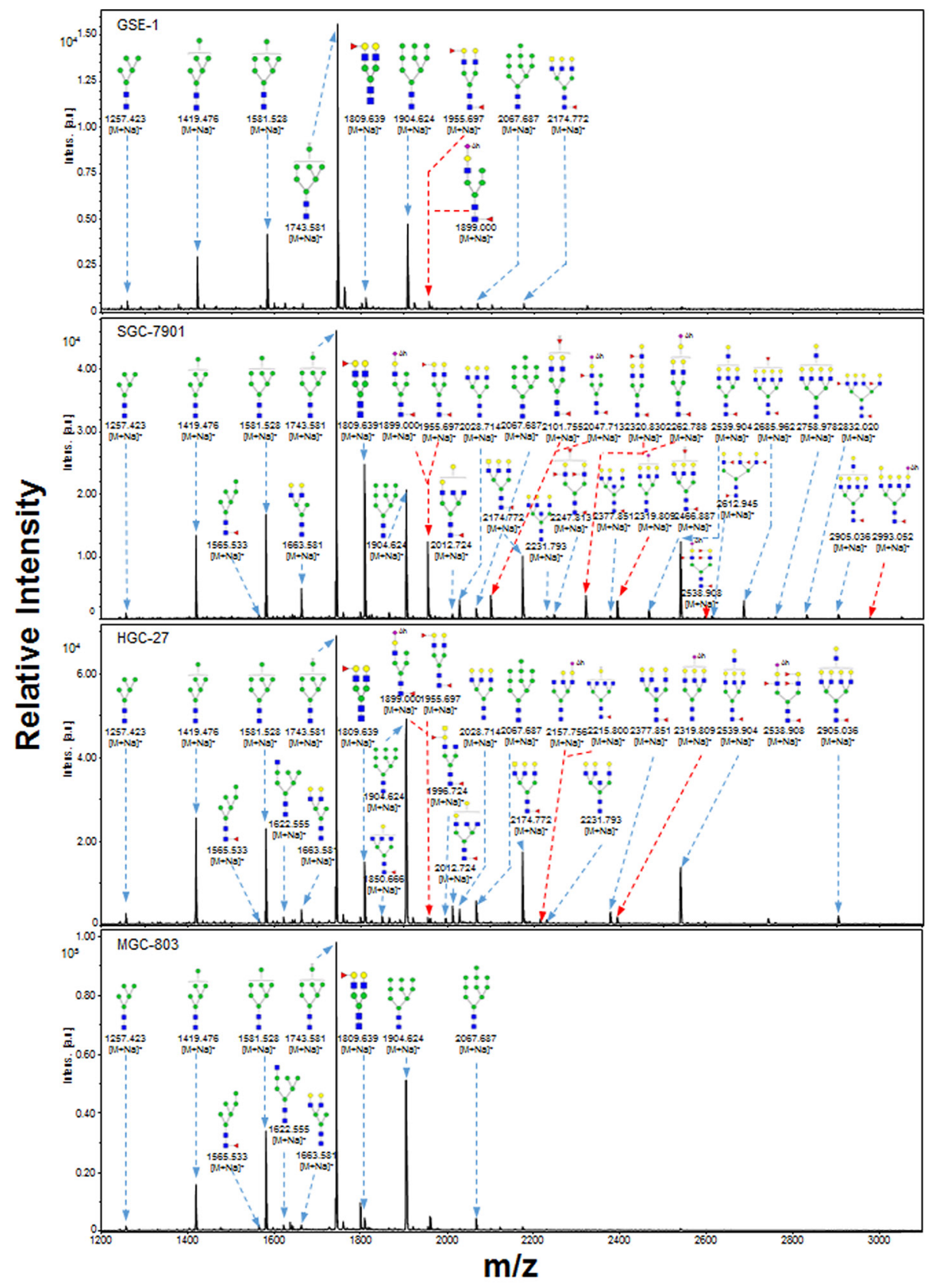

Figure 3: MALDI-TOF/TOF-MS spectra of total N-glycans in the four cell lines. N-glycans were characterized in the four cell lines (GES-1, SGC-7901, HGC-27, and MGC-803) by MALDI-TOF/TOF-MS as described in M\&M. Representative spectra from triplicate experiments are shown. Detailed glycan structures were analyzed using the GlycoWorkbench program. Proposed structures and their $\mathrm{m} / \mathrm{z}$ values are shown for each peak. 
Table 2: Proposed structures and their molecular ions in MALDI spectra of N-glycans in the four cell lines

\begin{tabular}{|c|c|c|c|c|c|c|c|c|}
\hline No. & Calculated & & Relativ & intensity & & Glycan & & \\
\hline & & GES-1 & SGC-7901 & HGC-27 & MGC-803 & & & \\
\hline 1 & 1257.423 & $0.048 \pm 0.001$ & $0.024 \pm 0.002$ & $0.078 \pm 0.045$ & $0.018 \pm 0.009$ & & - & - \\
\hline 2 & 1419.476 & $0.189 \pm 0.001$ & $0.352 \pm 0.080$ & $0.294 \pm 0.142$ & $0.172 \pm 0.008$ & - & - & - \\
\hline 3 & 1565.533 & - & 0.020 & 0.021 & $0.026 \pm 0.003$ & & - & - \\
\hline 4 & 1581.528 & $0.245 \pm 0.035$ & $0.365 \pm 0.052$ & $0.307 \pm 0.023$ & $0.351 \pm 0.008$ & & - & - \\
\hline 5 & 1622.555 & - & - & 0.021 & $0.025 \pm 0.018$ & & - & - \\
\hline 6 & 1663.581 & - & $0.104 \pm 0.011$ & 0.048 & $0.023 \pm 0.014$ & & - & - \\
\hline 7 & 1688.613 & & & $0.082 \pm 0.025$ & & & & \\
\hline 8 & 1743.581 & 1.000 & 1.000 & 1.000 & 1.000 & $\bullet$ & - & - \\
\hline 9 & 1809.639 & $0.059 \pm 0.022$ & $0.624 \pm 0.046$ & $0.199 \pm 0.044$ & $0.043 \pm 0.0004$ & & - & - \\
\hline 10 & 1850.666 & - & - & $0.054 \pm 0.041$ & - & $\vdots$ & - & - \\
\hline 11 & 1865.654 & - & $0.076 \pm 0.074$ & $0.039 \pm 0.030$ & - & $\vdots$ & - & - \\
\hline 12 & 1905.634 & $0.382 \pm 0.106$ & $0.438 \pm 0.066$ & $0.724 \pm 0.050$ & $0.476 \pm 0.003$ & & - & - \\
\hline 13 & 1955.697 & $0.048 \pm 0.025$ & $0.294 \pm 0.142$ & 0.020 & - & 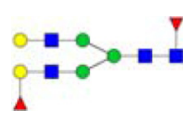 & - & - \\
\hline 14 & 1996.724 & - & - & 0.018 & - & 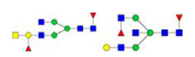 & - & - \\
\hline 15 & 2012.719 & - & $0.032 \pm 0.021$ & $0.078 \pm 0.026$ & 0.048 & 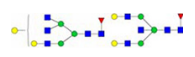 & - & - \\
\hline 16 & 2028.714 & & $0.054 \pm 0.015$ & $0.041 \pm 0.006$ & - & & - & - \\
\hline 17 & 2067.687 & $0.043 \pm 0.007$ & $0.045 \pm 0.007$ & $0.083 \pm 0.005$ & $0.044 \pm 0.003$ & & - & - \\
\hline 18 & 2101.755 & - & $0.053 \pm 0.038$ & - & - & & 2047.713 & $\because \infty 0$. \\
\hline 19 & 2174.772 & $0.036 \pm 0.020$ & $0.199 \pm 0.072$ & $0.216 \pm 0.089$ & - & 0 & - & - \\
\hline 20 & 2215.798 & - & - & $0.021 \pm 0.007$ & - & : & 2157.756 & $\because 0$ \\
\hline 21 & 2231.793 & - & $0.020 \pm 0.016$ & $0.026 \pm 0.018$ & - & $=0$ & - & - \\
\hline
\end{tabular}

(Continued) 


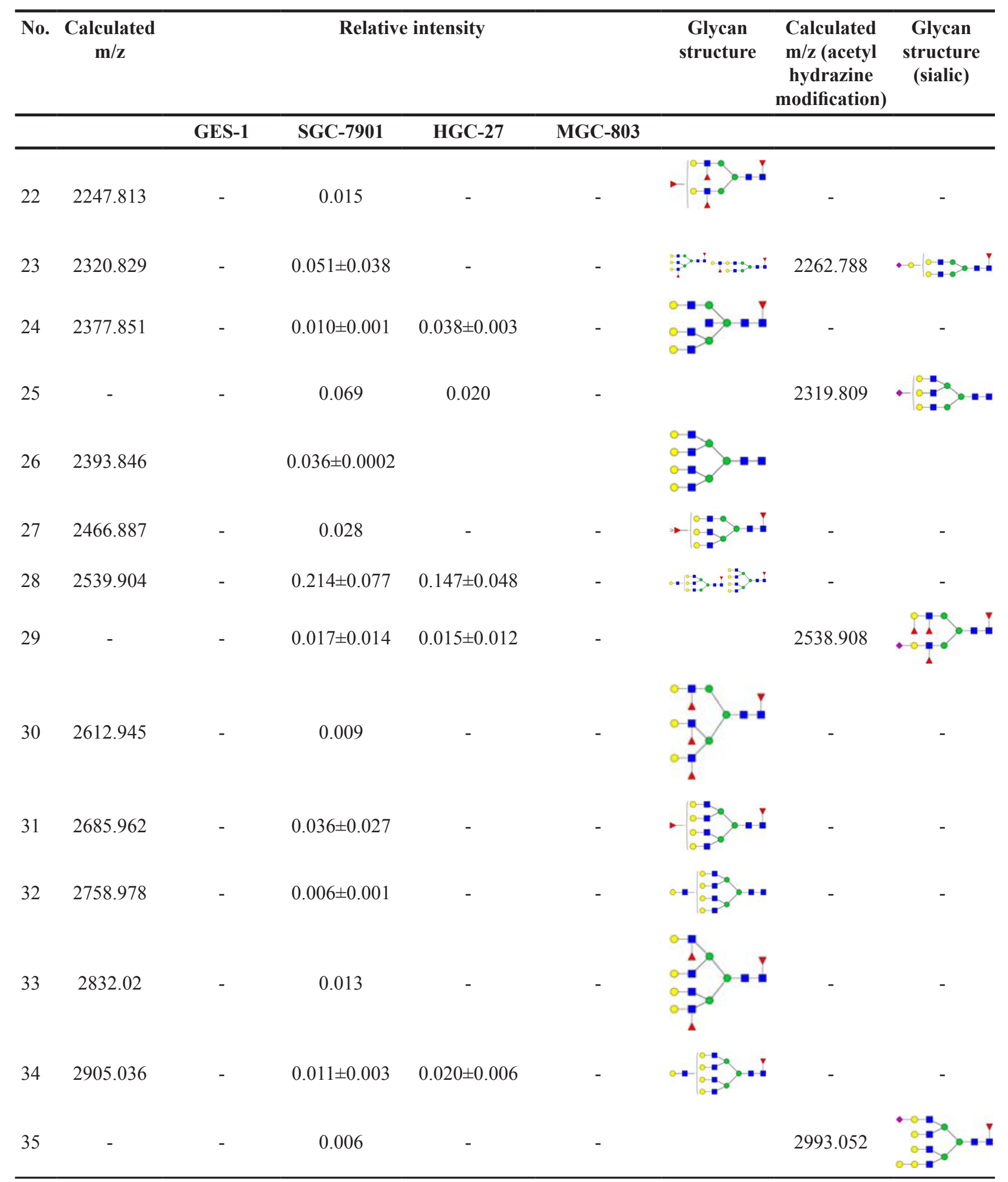
=GICNAC $\bigcirc=$ Gal $\bigcirc=$ Man $\bigcirc=$ Neu5Ac $\triangle$ =Fuc

$\mathrm{N}$-glycans with SD were identified in two independent experiments, and N-glycans without SD were identified in only one experiment. 


\section{DISCUSSION}

Altered (aberrant) expression of N-glycans, O-glycans, and other glycoconjugates is often associated with tumor development and progression [19-21]. Gastric cancer is the most common type of epithelial cancer worldwide; however, the functional roles of glycosylation in gastric cancer remain mostly unclear. Better understanding of these functional roles requires more sophisticated and comprehensive analytical techniques. In this study, we integrated By integrating lectin microarray analysis with mass spectrometry, we were able to globally profile glycan expression in gastric cancer cells, and validate aberrant glycan expression in clinical gastric cancer tissues using specific lectins.

Lectin-based methodology is capable of revealing glycan structures of all glycoconjugates, i.e., glycoproteins, glycolipids, and glycosaminoglycans [22]. There are

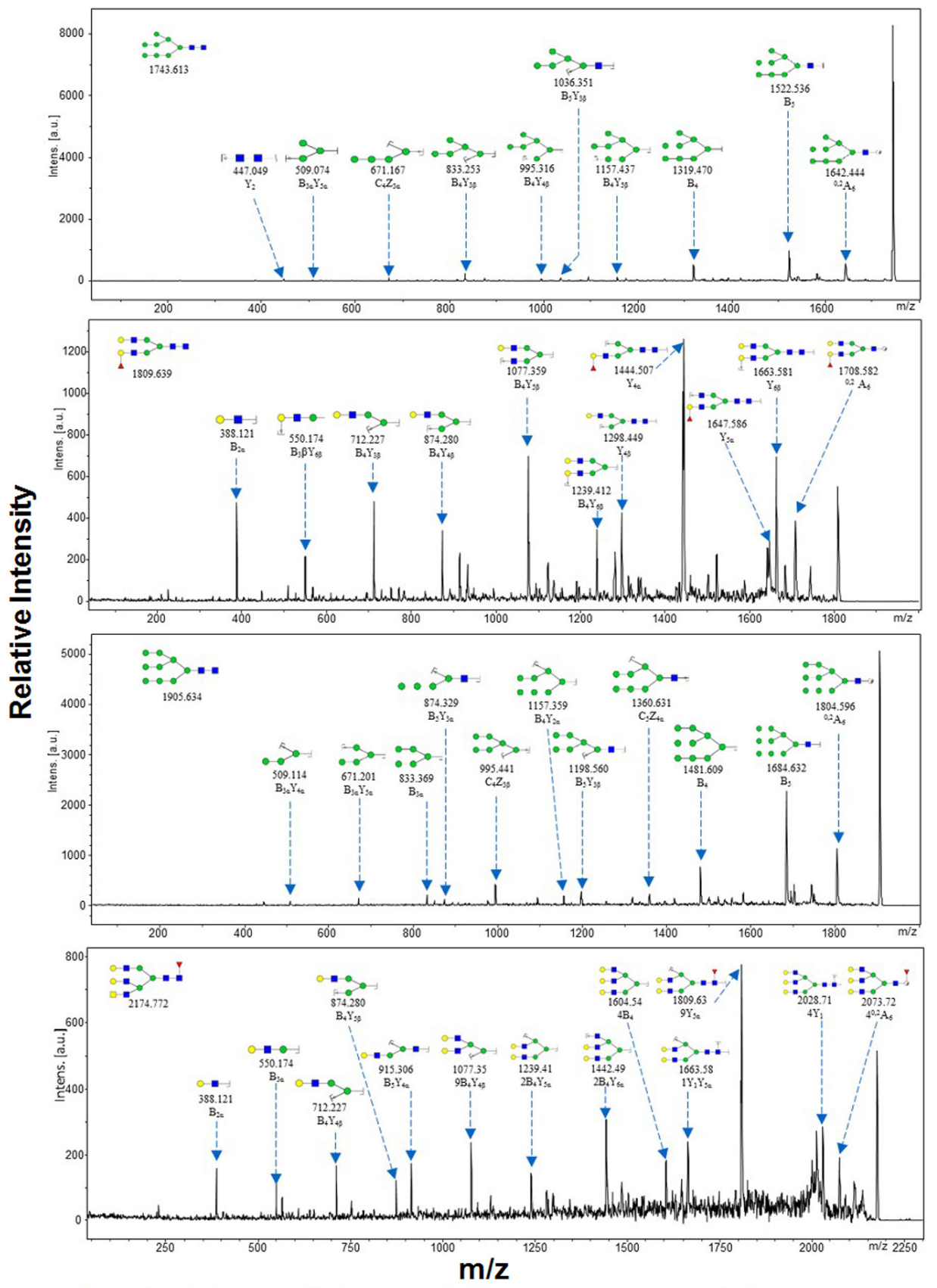

Figure 4: MALDI-TOF/TOF-MS/MS analysis of N-glycan precursor ions in MS spectra of the four cell lines. Precursor ions were subjected to MS/MS analysis to obtain cleavages, including B, Y, C, and Z glycosidic cleavages and A and X cross-ring cleavages. Structures of cleavage ions and $\mathrm{m} / \mathrm{z}$ values are shown in tandem mass spectra. The four major $\mathrm{N}$-glycan peaks are: $1743.613 \mathrm{~m} / \mathrm{z}, 1809.639$ $\mathrm{m} / \mathrm{z}, 1905.634 \mathrm{~m} / \mathrm{z}$, and $2174.772 \mathrm{~m} / \mathrm{z}$. 
Table 3: Relative variation of major types of $\mathrm{N}$-glycans in the four cell lines

\begin{tabular}{lcccc}
\hline Glycan type & GES-1 & SGC-7901 & HGC-27 & MGC-803 \\
\cline { 2 - 5 } & $\mathbf{( \% )}$ & $\mathbf{( \% )}$ & $\mathbf{( \% )}$ & $\mathbf{( \% )}$ \\
\hline High-mannose & 93.0 & 54.8 & 70.5 & 95.8 \\
Hybrid & 0.0 & 1.3 & 0.0 & 1.1 \\
Complex & 7.0 & 45.2 & 29.5 & 3.1 \\
$\quad$ Biantennary & 5.2 & 30.8 & 11.5 & 3.1 \\
$\quad$ Triantennary & 1.8 & 16.2 & 22.7 & 0 \\
$\quad$ Tetra-antennary & 0 & 7.5 & 5.3 & 0 \\
$\quad$ Sialylated & 0 & 3.0 & 1.2 & 0 \\
$\quad$ Fucosylated & 7.0 & 37.9 & 21.3 & 3.2 \\
\hline
\end{tabular}

three effective lectin-based methods: (i) Simultaneous quantitative analysis of $\mathrm{N}$-glycans and O-glycans using lectin microarrays with intact biological structures, following minimal sample preparation without release or derivatization of glycans [23, 24]. (ii) Lectin staining for identification and localization of glycoproteins and glycolipids in cells and tissues, and detection of subtle alterations in cellular glycosylation [25]. (iii) Lectin histochemistry, which is easily performed in a variety of cells, frozen or cryostat sections, and formalin-fixed or paraffin-embedded surgical specimens [26]. Combined application of these three methods ensures identification of correct glycosylation status in gastric cells or clinical samples. Using lectin microarray analysis, Huang et al. showed that VVA and MPL can be used as biomarkers to distinguish gastric cancer from gastric ulcer[12].

MS is a rapid and sensitive technique to detect glycan components and glycome profile of a biological sample [27]. The integrated strategy used in the present study and validation in both cell lines and clinical samples, led to several important findings. Gastric cancer cells showed clearly increased expression of core-fucosylated N-glycans, GalNAc $\alpha-S e r / T h r$ (Tn antigen), and Sia26Galß1-4GlcNAc N-glycans, but decreased expression of biantennary N-glycans, Gal $\beta 1$-3GalNAc $\alpha$-Ser/Thr (T antigen), and (GlcNAc) $)_{n} \mathrm{~N}$-glycans (Table 1).

Lectin microarray, lectin staining, and lectin histochemical analyses of gastric cancer cells and clinical samples revealed differential expression of core-fucosylation, biantennary $\mathrm{N}$-glycans, and $\mathrm{T}$ antigen (recognized by LCA, PHA-E $+\mathrm{L}$, and ACA, respectively), suggesting that these glycans are involved in development and progression of gastric cancer. There is increasing evidence for a role of core-fucose residue in a variety of physiological and pathological processes. Levels of corefucosylated $\mathrm{N}$-glycans (recognized by LCA) in certain serum proteins are undetectable in normal cells, but are higher in cancer cells [28-30]. On the other hand, Chen et al. observed lower total abundance of core-fucosylated residues in sera of gastric cancer patients [31]. In the present study, levels of core-fucosylated N-glycans were significantly higher in gastric cancer cells than in normal epithelial cells. Core-fucosylation, which is catalyzed by $\alpha 1,6$-fucosyltransferase (Fut8) in mammalian tissues, plays multiple roles in cancer. Increased core-fucosylation has been reported in prostate, ovarian, pancreatic, and non-small cell lung cancers [32]. High levels of corefucose were also observed during the process of epithelialmesenchymal transition [32]. Depletion of core-fucose in human IgG1 enhances antibody-dependent cell-mediated cytotoxicity during cancer therapy [33]. Disruption of the Fut8 gene in mice resulted in growth retardation, death during postnatal development, and lung emphysema [34].

In a study by Shimada et al., cancer patients and normal subjects showed similar levels of total free sialic acids [35]. However, levels of most sialylated oligosaccharides, and of $\alpha 2-3$ (but not $\alpha 2-6$ ) sialic acid that binds to lactose, were higher in advanced cancer patients than in normal subjects $[35,36]$. In the present study, $\alpha 2-6$ sialic acid (recognized by SNA) was higher in gastric cancer cells than in normal cells, but no significant difference was observed between clinical gastric cancer samples and corresponding normal tissues. Larger sample sizes of gastric cancer at various stages will be required to clarify this point.

A high concentration of Tn antigen on the surface of cancer cells is often associated with aggressive or highly malignant properties. $\mathrm{T}$ antigen is formed by addition of one Gal residue to GalNAc to yield Gal( $\beta 1-3)$ GalNAc. We observed lower levels of $\mathrm{T}$ antigen (recognized by ACA) in gastric cancer cells correspondence the results from lectin array and $\mathrm{O}$-glycan/ $\mathrm{N}$-glycan analysis, in contrast to previous reports of high $\mathrm{T}$ antigen levels in sera of gastric cancer patients [37]. A possible explanation of high Tn antigen level but low $\mathrm{T}$ antigen level in gastric cancer cells is the decreased enzymatic activity of $\beta 1,3-$ galactosyltransferase, which adds Gal to Tn substrate to form $\mathrm{T}$ antigen. Our survival analysis and multivariate 


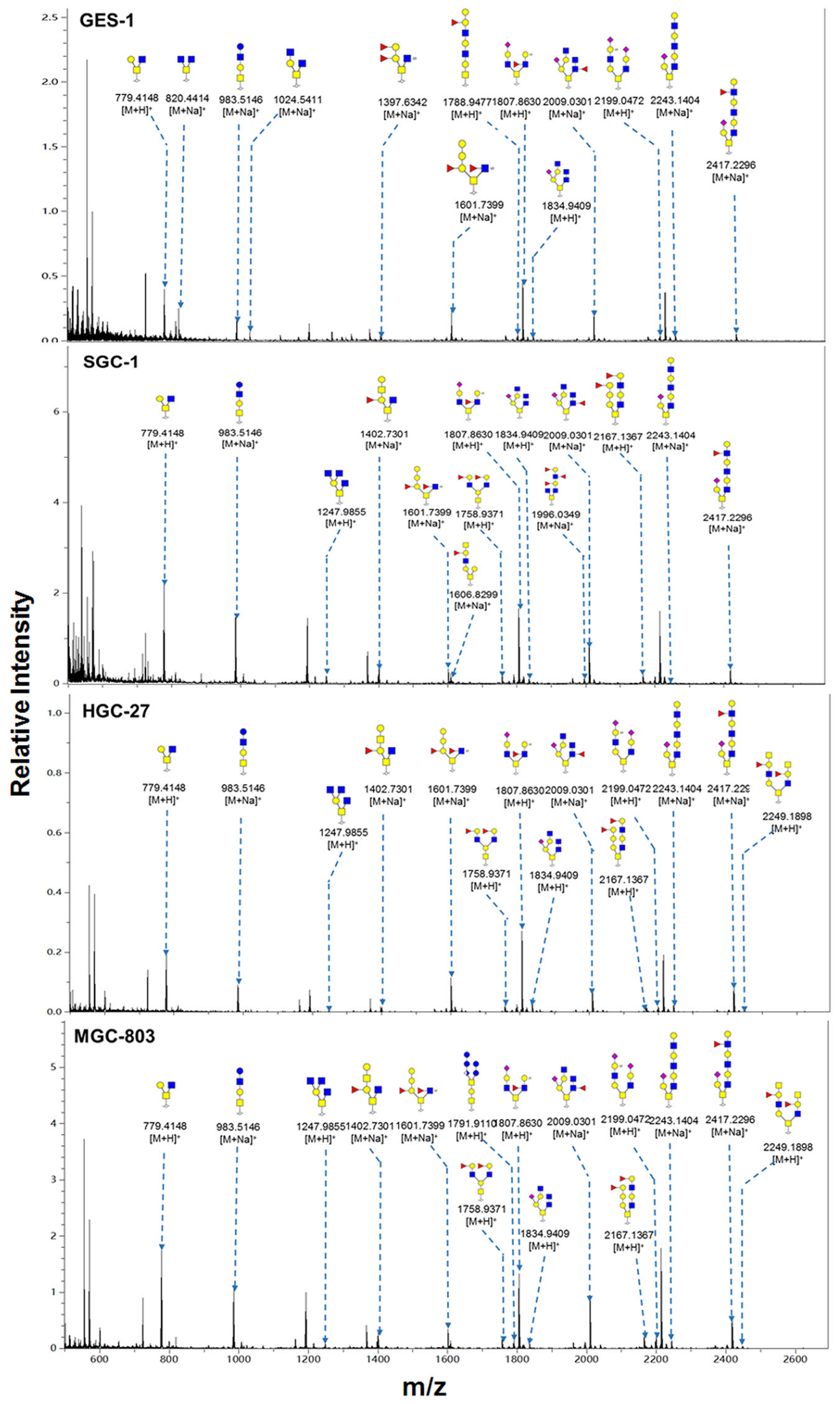

Figure 5: MALDI-TOF/TOF-MS spectra of total O-glycans in the four cell lines. O-glycans were characterized in the four cell lines (GES-1, SGC-7901, HGC-27, and MGC-803 cells) by MALDI-TOF/TOF-MS as described in M\&M. Representative spectra from triplicate experiments are shown. Detailed glycan structures were analyzed using the GlycoWorkbench program. Proposed structures and their $\mathrm{m} / \mathrm{z}$ values are shown for each peak. 
Table 4: Proposed structures and their molecular ions in MALDI spectra of O-linked glycans in the four cell lines

\begin{tabular}{|c|c|c|c|c|c|c|c|}
\hline \multirow[t]{2}{*}{ No. } & \multirow{2}{*}{$\begin{array}{c}\text { Calculated } \\
\mathrm{m} / \mathbf{z}\end{array}$} & \multicolumn{4}{|c|}{ Relative intensity } & \multirow[t]{2}{*}{ Glycan Structure } & \multirow[t]{2}{*}{ Type } \\
\hline & & GES-1 & SGC-7901 & HGC-27 & MGC-803 & & \\
\hline 1 & 512.307 & $0.1869 \pm 0.0011$ & $0.1799 \pm 0.0014$ & $0.0553 \pm 0.0001$ & $0.0680 \pm 0.0002$ & Ǵ & core 1 \\
\hline 2 & 575.315 & & $0.2947 \pm 0.0010$ & & & $\square-\dot{q}$ & core 3,5 \\
\hline 3 & 600.23 & $0.0813 \pm 0.0005$ & & $0.2438 \pm 0.0012$ & $0.1167 \pm 0.0004$ & & core 1 \\
\hline 4 & 779.415 & $0.1401 \pm 0.0003$ & $0.1502 \pm 0.0006$ & & & bets & core $1,2,3$ \\
\hline 5 & 798.459 & & & & $0.0351 \pm 0.0002$ & $\square-8$ & core 4,5 \\
\hline 6 & 820.441 & $0.0717 \pm 0.0003$ & & $0.0396 \pm 0.0001$ & $0.0641 \pm 0.0003$ & $\square-8$ & core 4,5 \\
\hline 7 & 983.515 & $0.0789 \pm 0.0002$ & $0.0848 \pm 0.0005$ & $0.1347 \pm 0.0007$ & $0.1031 \pm 0.0006$ & & core $1,2,6$ \\
\hline 8 & 1024.541 & 0.0258 & & $0.0308 \pm 0.0001$ & $0.0325 \pm 0.0002$ & & core $2,4,6$ \\
\hline 9 & 1069.551 & & & & $0.0186 \pm 0.0001$ & & core 1 \\
\hline 10 & 1247.986 & & 0.0122 & $0.0309 \pm 0.0003$ & $0.0203 \pm 0.0001$ & & core 2 \\
\hline 11 & 1380.748 & & $0.0082 \pm 0.0001$ & & & 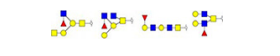 & Core $1,2,3,4$ \\
\hline 12 & 1383.711 & & & 0.0102 & 0.0073 & & core 8 \\
\hline 13 & 1397.634 & $0.0220 \pm 0.0001$ & $0.0231 \pm 0.0001$ & $0.0286 \pm 0.0001$ & $0.0306 \pm 0.0001$ & & core 2 \\
\hline 14 & 1402.73 & & $0.0282 \pm 0.0002$ & & $0.0202 \pm 0.0001$ & 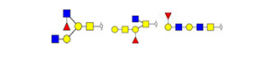 & core $1,2,3$ \\
\hline 15 & 1421.775 & & & & $0.0145 \pm 0.0001$ & 5 & core 2,4 \\
\hline 16 & 1584.848 & 0.0069 & & 0.0105 & & 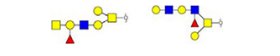 & core 1,2 \\
\hline 17 & 1587.811 & & & $0.0150 \pm 0.0001$ & 0.0097 & -6 & core 8 \\
\hline 18 & 1601.74 & $0.1004 \pm 0.0002$ & $0.0348 \pm 0.0002$ & $0.1524 \pm 0.0005$ & $0.0819 \pm 0.0003$ & $\begin{array}{l}\Delta-6 \\
\Delta\end{array}$ & core 2 \\
\hline 19 & 1606.83 & & 0.0059 & 0.0118 & 0.0113 & at & core 1,2 \\
\hline 20 & 1614.859 & 0.0071 & & & & 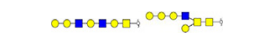 & core 1,5 \\
\hline 21 & 1758.937 & $0.0210 \pm 0.0001$ & $0.0234 \pm 0.0001$ & $0.0408 \pm 0.0001$ & $0.0333 \pm 0.0001$ & $\boldsymbol{\Delta}$ & core 1 \\
\hline & & & & & & & (Continued) \\
\hline
\end{tabular}




\begin{tabular}{|c|c|c|c|c|c|c|c|}
\hline \multirow[t]{2}{*}{ No. } & \multirow{2}{*}{$\begin{array}{c}\text { Calculated } \\
\mathbf{m} / \mathbf{z}\end{array}$} & \multicolumn{4}{|c|}{ Relative intensity } & \multirow[t]{2}{*}{ Glycan Structure } & \multirow[t]{2}{*}{ Type } \\
\hline & & GES-1 & SGC-7901 & HGC-27 & MGC-803 & & \\
\hline 22 & 1777.932 & & 0.0061 & & & $\begin{array}{l}0-0=0 \\
0-0-0 \\
0-9\end{array}$ & core 2 \\
\hline 23 & 1788.948 & 0.0106 & $0.0108 \pm 0.0001$ & $0.0209 \pm 0.0001$ & 0.0099 & & core 1 \\
\hline 24 & 1791.911 & $0.0213 \pm 0.0001$ & $0.0161 \pm 0.0001$ & & $0.0144 \pm 0.0001$ & & core 8 \\
\hline 25 & 1834.941 & $0.0296 \pm 0.0001$ & $0.0136 \pm 0.0001$ & $0.0370 \pm 0.0001$ & $0.0275 \pm 0.0001$ & 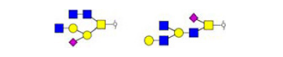 & core 2,3 \\
\hline 26 & 1857.969 & & & 0.0132 & & $-0^{\circ}$ & core 1,2 \\
\hline 27 & 1963.037 & 0.0077 & 0.0127 & & 0.0155 & & core 1 \\
\hline 28 & 1996.035 & $0.0137 \pm 0.0001$ & $0.0122 \pm 0.0001$ & 0.0105 & 0.0143 & & core 2,4 \\
\hline 29 & 2009.03 & $0.1310 \pm 0.0006$ & $0.1006 \pm 0.000$ & $0.0752 \pm 0.0003$ & $0.1404 \pm 0.0004$ & & core 2 \\
\hline 30 & 2039.041 & $0.0177 \pm 0.0001$ & & 0.0103 & 0.0140 & & core 2 \\
\hline 31 & 2167.137 & $0.0259 \pm 0.0002$ & $0.0215 \pm 0.0001$ & $0.0187 \pm 0.0001$ & $0.0291 \pm 0.0001$ & & core 1,2 \\
\hline 32 & 2199.047 & $0.0279 \pm 0.0001$ & & $0.0 .45 \pm 0.0001$ & $0.0208 \pm 0.0001$ & & core 2 \\
\hline 33 & 2243.14 & $0.0421 \pm 0.000$ & $0.0177 \pm 0.0001$ & $0.0233 \pm 0.0001$ & $0.0298 \pm 0.0001$ & & core 1 \\
\hline 34 & 2370.204 & & & 0.0082 & 0.0076 & 마요 & core 3 \\
\hline 35 & 2417.23 & $0.0841 \pm 0.0007$ & $0.0434 \pm 0.0001$ & $0.0648 \pm 0.0003$ & $0.0764 \pm 0.0002$ & & core 2 \\
\hline 36 & 2249.16 & & & 0.0094 & 0.0085 & 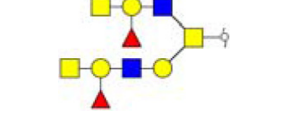 & core 2 \\
\hline
\end{tabular}

analyses showed that prognosis was significantly worse for patients with low (vs. high) ACA binding capacity, suggesting that glycans recognized by ACA are potential prognostic factors for gastric cancer.

PHA-E $+\mathrm{L}$ includes PHA-E and PHA-L, which recognize bisecting GlcNAc and biantennary N-glycans, respectively. Overexpression of bisecting GlcNAc inhibited tumor progression in mice, perhaps through an effect on growth factor signaling [38]. Our lectin microarray analysis revealed no significant changes in bisecting GlcNAc, and reduced expression of biantennary $\mathrm{N}$-glycans was observed in gastric cancer cells and clinical cancer tissue samples. We consider biantennary N-glycan as the novel identified $\mathrm{N}$-glycan in this study.

Taken together, our findings from lectin microarray analysis, MS, and histochemical staining demonstrate increased expression of Tn antigen, N-glycan structures, and core-fucosylated $\mathrm{N}$-glycans, and reduced expression of $\mathrm{T}$ antigen and biantennary $\mathrm{N}$-glycans in gastric cancer cells and clinical samples. Our follow-up studies, in progress, are focused on alterations of these glycans and their related genes at the molecular level, the glycoproteins to which the altered glycans bind, and the roles of these glycans in functional modulation of the glycoproteins in gastric cancer. 

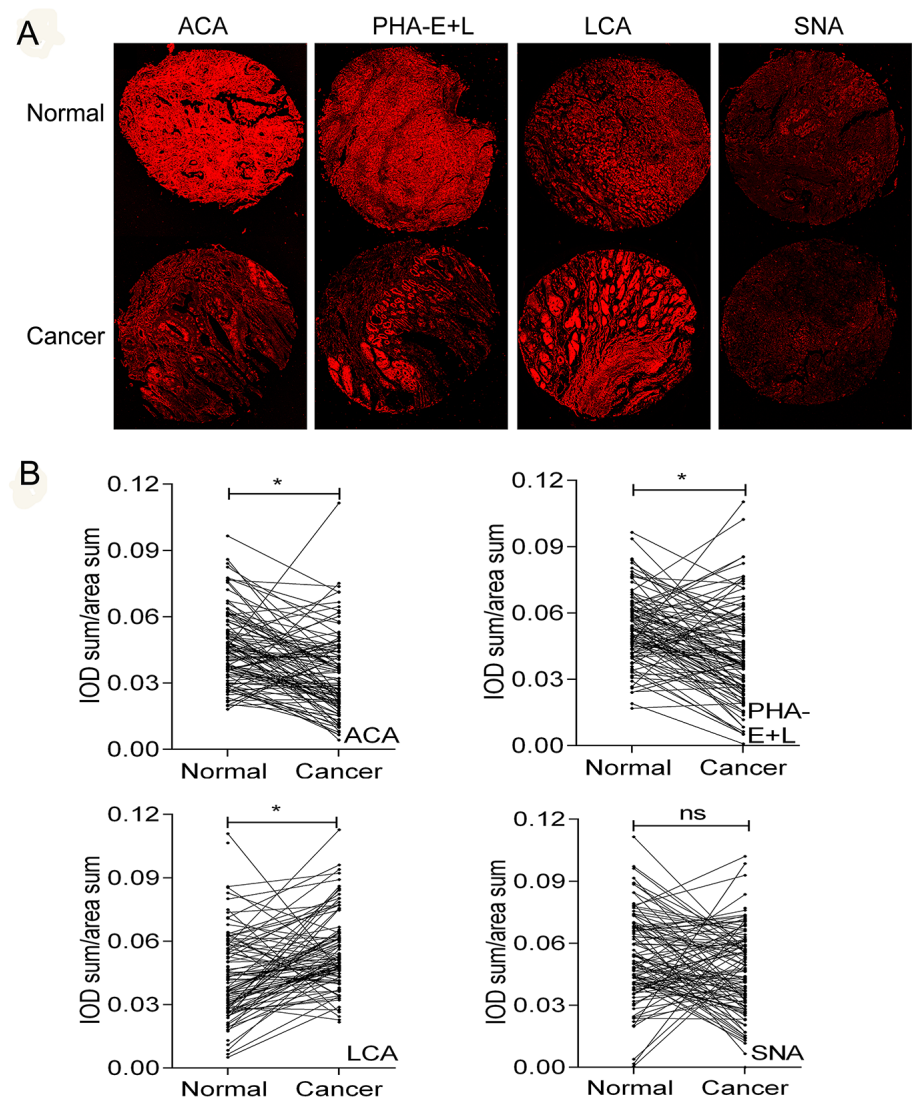

Figure 6: Differential glycopatterns in gastric cancer and normal gastric epithelial tissues evaluated by lectin histochemistry. Four lectins (ACA, LCA, PHA-E+L, SNA) were used. Lectin histochemistry was performed in duplicate, and representative photos are shown (A and B). Normal: normal adjacent tissues. Cancer: gastric cancer tissues. IOD: integrated optical density Objective magnification: 10x. Scale bars: $200 \mu \mathrm{m}$.
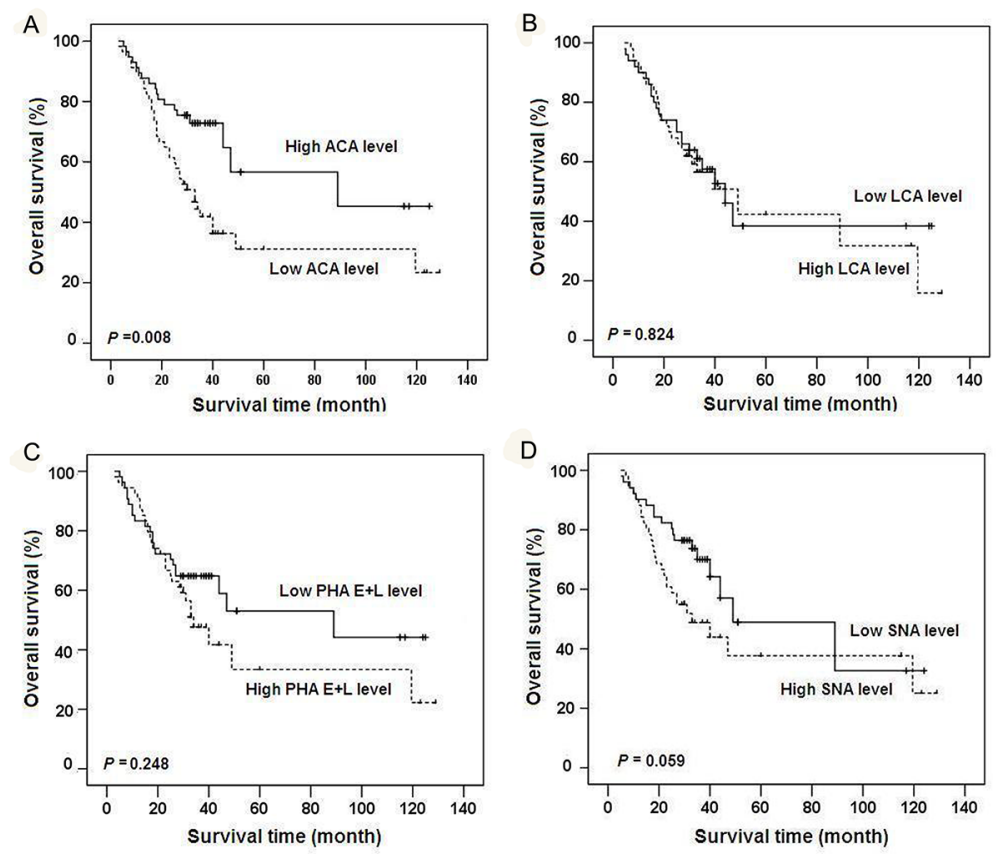

Figure 7: Kaplan-Meier overall survival curves for gastric cancer patients classified according to relative expression levels of four lectins. Patients were classified into "relatively high" and "relatively low" groups using the median expression level of ACA A., LCA B., PHA-E+L C., or SNA D. in gastric cancer tissues as respective cutoff value. 


\section{MATERIALS AND METHODS}

\section{Cell lines and clinical samples}

Gastric cancer cell lines SGC-7901 (metastatic stomach adenocarcinoma derived cell), HGC-27 (undifferentiated stomach adenocarcinoma cell), and MGC-803 (poorly differentiated stomach mucinous adenocarcinoma cell), and immortalized normal gastric epithelial cell line GES-1, were obtained from the Cell Bank of the Chinese Academy of Sciences (Shanghai). All cells were cultured in RPMI 1640 (HyClone; Logan, UT, USA) containing 10\% fetal bovine serum (Gibco; Carlsbad, CA, USA) and $1 \times$ penicillin/ streptomycin (Gibco) at $37{ }^{\circ} \mathrm{C}$ in $5 \% \mathrm{CO}_{2}$ atmosphere.

Tissue microarrays including 120 pairs of gastric tissues and adjacent normal tissues (Supplementary Table S1) were supplied by the Affiliated Hospital of Jiangnan University. All patient materials were obtained with written informed consent from all subjects. This study and all the experimental protocols were approved by the Clinical Research Ethics Committee of Affiliated Hospital of Jiangnan University. All the study methods were consistent with the guidelines approved by the Committee.

\section{Total protein extraction}

Cells (at $80-90 \%$ confluence) were lysed with Tissue Protein Extraction Reagent (T-PER) (Thermo Scientific; San Jose, CA, USA) according to the manufacturer's instructions. Protein content was determined by BCA assay (Beyotime; Shanghai).

\section{Lectin microarray analysis}

Lectin microarray analysis was performed as described previously [39-41]. In brief, 37 commercial lectins from Vector Laboratories (Burlingame, CA, USA), Sigma-Aldrich (St Louis, MO, USA), and Calbiochem Merck (Darmstadt, Germany) were immobilized on a solid support at high spatial density. Glycoprotein samples labeled with fluorescent dye Cy3 (GE Healthcare; Buckinghamshire, UK) were applied and scanned with a GenePix 4000B confocal scanner (Axon Instruments; Union City, CA, USA). Raw values less than the mean background value were omitted from analysis. The median for each lectin was globally normalized to the sum of medians of all valid data for the 37 lectins. Each sample was repeated tested in three lectin microarrays and the mean value of each lectin from 3 repeated arrays and its SD were calculated.

\section{Lectin staining}

Cells were cultured in 24-well plates with sterilized glycergel (DakoCytomation; Carpinteria, CA, USA) to 60-70\% confluence, and stained with Cy3-labeled lectins (ACA, PHA-E+L, LCA, SNA) as described previously ${ }^{14}$.

\section{Separation of N-glycans, and amidation of sialylated $\mathbf{N}$-glycans}

Proteins $(2 \mathrm{mg})$ from each cell line were concentrated and desalted using a size-exclusion spin ultrafiltration unit (Amicon Ultra-0.5 $10 \mathrm{KD}$, Millipore; Billerica, MA, USA) as described previously $[39,42,43]$. In brief, proteins were denatured with $8 \mathrm{M}$ urea, $10 \mathrm{mM}$ DTT, and $20 \mathrm{mM}$ IAM (Sigma-Aldrich), and centrifuged. Samples were washed with $50 \mathrm{mM}$ $\mathrm{NH}_{4} \mathrm{HCO}_{3}$, and desalted by washing with deionized water. The desalted proteins were redissolved with $100 \mu \mathrm{L}$ of $1 \mathrm{M}$ acetohydrazide (Sigma-Aldrich), $20 \mu \mathrm{L}$ of $1 \mathrm{M} \mathrm{HCl}$, and $20 \mu \mathrm{L}$ of $2 \mathrm{M}$ EDC (1-ethyl-3-(3-dimethyllaminopropyl) carbodiimide hydrochloride) (Sigma-Aldrich). The mixture was incubated at room temperature for $4 \mathrm{~h}$ to amidate sialylated $\mathrm{N}$-glycans. The sample was further digested with PNGase F (New England BioLabs; Ipswich, MA, USA) (1:1000) overnight at $37{ }^{\circ} \mathrm{C}$. Released amidated $\mathrm{N}$-glycans were collected and lyophilized.

\section{Desalting of N-glycans}

Desalting was performed using Sepharose 4B (Sigma-Aldrich) as described previously [44]. Sepharose 4B in a microtube was washed with methanol/ $\mathrm{H}_{2} \mathrm{O}(1: 1$ $\mathrm{v} / \mathrm{v})(\mathrm{MW})$ and 1-butanol/ methanol/ $\mathrm{H}_{2} \mathrm{O}(5: 1: 1 \mathrm{v} / \mathrm{v} / \mathrm{v})$ (BMW) under centrifugation. Glycans were dissolved in $500 \mu \mathrm{L} \mathrm{BMW}$ and added to the microtube. The mixture was gently shaken for $45 \mathrm{~min}$ and washed three times with BMW. N-glycans were eluted with MW, collected, and lyophilized.

\section{Separation and permethylated derivatization of O-linked glycans}

Glycoproteins were subjected to modify $\beta$-elimination protocol. The proteins were denatured and desalted using a size-exclusion spin ultrafiltration unit. $300 \mu \mathrm{L}$ ammonia- borane complex, prepared in $28 \%$ ammonium hydroxide were added to samples and incubated for $24 \mathrm{~h}$ at $37^{\circ} \mathrm{C}$ and subsequently cool to room temperature prior to the addition of sufficient $1 \mathrm{M} \mathrm{HCl}$ to neutralize any residual ammonia - borane complex and ammonium hydroxide. This step was conducted in an ice bath. The samples were lyophilized, methanolwashed, and then dried three times to remove residual borate [45]. The glycans were cleaned-up using carbon SPE column (Grace Davison Discovery Sciences, USA) and then lyophilized. The resulting reduced glycans were subsequently subjected to permethylated derivatization. Four $\mathrm{NaOH}$ pellets (approximately $500 \mathrm{mg}$ ) were crushed in $10 \mathrm{~mL}$ anhydrous DMSO; $200 \mu \mathrm{L}$ of this slurry and $50 \mu \mathrm{L} \mathrm{CH}_{3} \mathrm{I}$ were then added to the dried glycans and the mixture was shaken vigorously for 20-30 mins. The mixture was extracted five times sequentially with a mixture of $2 \mathrm{~mL}$ water and $1 \mathrm{~mL}$ chloroform. Finally, the 
combined chloroform phases were dried under nitrogen. The permethylated O-glycans were further purified through carbon SPE column [46].

\section{Mass spectrometry}

$\mathrm{N}$-glycans were characterized by MALDI-TOF/ TOF-MS (UltrafleXtreme, Bruker Daltonics; Bremen, Germany). Lyophilized N-glycans were resuspended in $5 \mu \mathrm{L} \mathrm{MW}$, and $1 \mu \mathrm{L}$ of the mixture was spotted onto an MTP AnchorChip sample target and air-dried. One $\mu \mathrm{L}$ of $20 \mathrm{mg} / \mathrm{mL}$ 2,5-dihydroxybenzoic acid (DHB) in MW was spotted to recrystallize the glycans. Mass calibration was performed using peptide calibration standards (250 calibration points; Bruker). Measurements were taken in positive-ion mode and the intense ions from MS spectra were subsequently selected and subjected to MS/MS. Representative MS spectra of N-glycans with signalto-noise ratios $>3$ were chose and annotated using the GlycoWorkbench program with the accuracy $<1.0$ (http:// code.google.com/p/glycoworkbench/). Relative intensities were analyzed and generated using the FlexAnalysis software program (Bruker Daltonics). Relative variation was calculated by dividing the relative intensity of a particular type of $\mathrm{N}$-glycan by the sum of N-glycan relative intensity in one scan, as described previously [47].

\section{Lectin histochemistry}

Lectin histochemistry staining was performed on 4-mm sections of paraffin-embedded tissue samples for detection of lectin expression levels, as described previously ${ }^{14}$. Representative area and fluorescence intensity of tissue dots were measured using the Image-Pro Plus 6.0 software program (Media Cybernetics; Carlsbad, CA, USA) $[48,49]$.

\section{Statistical analyses}

The quantitative or qualitative data was subjected to the Mann-Whitney $U$ test or $\chi^{2}$ test, respectively. Spearman correlation analysis was performed to evaluate potential relationship between different variables. The survival curves were plotted according to the KaplanMeier method and verified by the log-rank test. Cox proportional hazards regression analysis was used to estimate the HRs and the $95 \%$ confidence intervals (CI). A value of $P<0.05$ was considered to be statistically significant.

\section{ACKNOWLEDGMENTS}

This study was supported in part by grants from the National Natural Science Foundation of China (81470294, 31400691, 81272299, and 81672328), Natural Science Foundation of Jiangsu Province (BK20140169, BK20150004, and BK20151108), the
Fundamental Research Funds for the Central Universities (NOJUSRP51619B), Medical Key Professionals Program of Jiangsu Province (RC2011031), “333” Talents Project of Jiangsu Province, and a Program from Hospital Management Center of Wuxi (YGZXM1401). The authors are grateful to Dr. S. Anderson for English editing of the manuscript.

\section{CONFLICTS OF INTEREST}

The authors declare no conflicts of interest.

\section{Author contributions}

X.L. and Z.H.H. designed the study and wrote the manuscript. X.L., D.L.L., and Z.Q.T. performed the experiments. F.G., Y.L.W., and G.L.Y. performed the statistical analyses and critiqued the manuscript. Z.H.H. collected all tumor specimens and clinical pathological data. All authors read and approved the final manuscript.

\section{REFERENCES}

1. Cunningham D, Jost LM, Purkalne G, Oliveira J and Force EGT. ESMO Minimum Clinical Recommendations for diagnosis, treatment and follow-up of gastric cancer. Ann Oncol. 2005; 16:i22-23.

2. Jemal A, Bray F, Center MM, Ferlay J, Ward E and Forman D. Global cancer statistics. CA Cancer J Clin. 2011; 61:69-90.

3. Jing JJ, Liu HY, Hao JK, Wang LN, Wang YP, Sun LH and Yuan Y. Gastric cancer incidence and mortality in Zhuanghe, China, between 2005 and 2010. World J Gastroenterol. 2012; 18:1262-1269.

4. Yang L. Incidence and mortality of gastric cancer in China. World J Gastroenterol. 2006; 12:17-20.

5. Ono H. Early gastric cancer: diagnosis, pathology, treatment techniques and treatment outcomes. Eur J Gastroenterol Hepatol. 2006; 18:863-866.

6. Apweiler R, Hermjakob H and Sharon N. On the frequency of protein glycosylation, as deduced from analysis of the SWISS-PROT database. Biochim Biophys Acta. 1999; 1473:4-8.

7. Li M, Song L and Qin X. Glycan changes: cancer metastasis and anti-cancer vaccines. J Biosci. 2010; 35:665-673.

8. David L, Nesland JM, Clausen H, Carneiro F and SobrinhoSimoes M. Simple mucin-type carbohydrate antigens (Tn, sialosyl-Tn and T) in gastric mucosa, carcinomas and metastases. APMIS Suppl. 1992; 27:162-172.

9. Nakasaki H, Mitomi T, Noto T, Ogoshi K, Hanaue H, Tanaka Y, Makuuchi H, Clausen H and Hakomori $\mathrm{S}$. Mosaicism in the expression of tumor-associated carbohydrate antigens in human colonic and gastric cancers. Cancer Res. 1989; 49:3662-3669. 
10. Nakagoe T, Sawai T, Tsuji T, Jibiki MA, Nanashima A, Yamaguchi H, Yasutake T, Ayabe H, Arisawa K and Ishikawa H. Predictive factors for preoperative serum levels of sialy Lewis(x), sialyl Lewis(a) and sialyl Tn antigens in gastric cancer patients. Anticancer Res. 2002; 22:451-458.

11. Ishizuka A, Hashimto Y, Naka R, Kinoshita M, Kakehi K, Seino J, Funakoshi Y, Suzuki T, Kameyama A and Narimatsu H. Accumulation of free complex-type N-glycans in MKN7 and MKN45 stomach cancer cells. Biochemical J. 2008; 413:227-237.

12. Huang WL, Li YG, Lv YC, Guan XH, Ji HF and Chi BR. Use of lectin microarray to differentiate gastric cancer from gastric ulcer. World J Gastroenterol. 2014; 20:5474-5482.

13. Zhang X, Wang Y, Qian Y, Wu X, Zhang Z, Liu X, Zhao R, Zhou L, Ruan Y, Xu J, Liu H, Ren S, Xu C and Gu J. Discovery of specific metastasis-related N-glycan alterations in epithelial ovarian cancer based on quantitative glycomics. PloS one. 2014; 9:e87978.

14. Kannicht C, Lucka L, Nuck R, Reutter W and Gohlke M. $\mathrm{N}$-glycosylation of the carcinoembryonic antigen related cell adhesion molecule, C-CAM, from rat liver: detection of oversialylated bi- and triantennary structures. Glycobiology. 1999; 9:897-906.

15. Gu J, Isaji T, Xu Q, Kariya Y, Gu W, Fukuda T and Du Y. Potential roles of N-glycosylation in cell adhesion. Glycoconjugate J. 2012; 29:599-607.

16. Meany DL and Chan DW. Aberrant glycosylation associated with enzymes as cancer biomarkers. Clin Proteomics. 2011; 8:10.1186.

17. Adamczyk B, Tharmalingam T and Rudd PM. Glycans as cancer biomarkers. Biochim Biophys Acta. 2012; 1820:1347-1353.

18. Balog CI, Stavenhagen K, Fung WL, Koeleman CA, McDonnell LA, Verhoeven A, Mesker WE, Tollenaar RA, Deelder AM and Wuhrer M. N-glycosylation of colorectal cancer tissues: a liquid chromatography and mass spectrometry-based investigation. Mol Cell Proteomics. 2012; 11:571-585.

19. Saldova R, Royle L, Radcliffe CM, Hamid UMA, Evans R, Arnold JN, Banks RE, Hutson R, Harvey DJ and Antrobus R. Ovarian cancer is associated with changes in glycosylation in both acute-phase proteins and $\mathrm{IgG}$. Glycobiology. 2007; 17:1344-1356.

20. de Leoz ML, Young LJ, An HJ, Kronewitter SR, Kim J, Miyamoto S, Borowsky AD, Chew HK and Lebrilla CB. High-mannose glycans are elevated during breast cancer progression. Mol Cell Proteomics. 2011; 10:M110 002717.

21. Campbell BJ, Yu LG and Rhodes JM. Altered glycosylation in inflammatory bowel disease: a possible role in cancer development. Glycoconjugate J. 2001; 18:851-858.

22. Goodarzi MT and Turner GA. A lectin method for investigating the glycosylation of nanogram amounts of purified glycoprotein. Glycoconjugate J. 1997; 14:493-496.

23. Kuno A, Uchiyama N, Koseki-Kuno S, Ebe Y, Takashima S, Yamada $\mathrm{M}$ and Hirabayashi J. Evanescent-field fluorescence-assisted lectin microarray: a new strategy for glycan profiling. Nat Methods. 2005; 2:851-856.

24. Tateno H, Uchiyama N, Kuno A, Togayachi A, Sato T, Narimatsu $\mathrm{H}$ and Hirabayashi J. A novel strategy for mammalian cell surface glycome profiling using lectin microarray. Glycobiology. 2007; 17:1138-1146.

25. Qin Y, Zhong Y, Dang L, Zhu M, Yu H, Chen W, Cui J, Bian $\mathrm{H}$ and $\mathrm{Li} \mathrm{Z}$. Alteration of protein glycosylation in human hepatic stellate cells activated with transforming growth factor-beta1. J Proteomics. 2012; 75:4114-4123.

26. Meyer W, Godynicki S and Tsukise A. Lectin histochemistry of the endothelium of blood vessels in the mammalian integument, with remarks on the endothelial glycocalyx and blood vessel system nomenclature. Ann Anat. 2008; 190:264-276.

27. An HJ, Kronewitter SR, de Leoz ML and Lebrilla CB. Glycomics and disease markers. Curr Opin Chem Biol. 2009; 13:601-607.

28. Yamashita K, Liang CJ, Funakoshi S and Kobata A. Structural studies of asparagine-linked sugar chains of human ceruloplasmin. Structural characteristics of the triantennary complex type sugar chains of human plasma glycoproteins. J Biol Chem. 1981; 256:1283-1289.

29. Yamashita K, Ideo H, Ohkura T, Fukushima K, Yuasa I, Ohno K and Takeshita K. Sugar chains of serum transferrin from patients with carbohydrate deficient glycoprotein syndrome. Evidence of asparagine-N-linked oligosaccharide transfer deficiency. J Biol Chem. 1993; 268:5783-5789.

30. Miyoshi E, Noda K, Yamaguchi Y, Inoue S, Ikeda Y, Wang W, Ko JH, Uozumi N, Li W and Taniguchi N. The alpha16-fucosyltransferase gene and its biological significance. Biochim Biophys Acta. 1999; 1473:9-20.

31. Chen J, Fang M, Zhao YP, Yi CH, Ji J, Cheng C, Wang MM, Gu X, Sun QS, Chen XL and Gao CF. Serum N-Glycans: A New Diagnostic Biomarker for Light Chain Multiple Myeloma. PloS one. 2015; 10:e127022.

32. Miura Y, Hashii N, Tsumoto H, Takakura D, Ohta Y, Abe Y, Arai Y, Kawasaki N, Hirose N, Endo T and Sonic. Change in N-Glycosylation of Plasma Proteins in Japanese Semisupercentenarians. PloS one. 2015; 10:e0142645.

33. Shinkawa T, Nakamura K, Yamane N, Shoji-Hosaka E, Kanda Y, Sakurada M, Uchida K, Anazawa H, Satoh M, Yamasaki $\mathrm{M}$, Hanai $\mathrm{N}$ and Shitara $\mathrm{K}$. The absence of fucose but not the presence of galactose or bisecting $\mathrm{N}$-acetylglucosamine of human IgG1 complex-type oligosaccharides shows the critical role of enhancing antibody-dependent cellular cytotoxicity. J Biol Chem. 2003; 278:3466-3473.

34. Wang $\mathrm{X}$, Inoue $\mathrm{S}, \mathrm{Gu} \mathrm{J}$, Miyoshi E, Noda K, Li W, Mizuno-Horikawa Y, Nakano M, Asahi M, Takahashi M, Uozumi N, Ihara S, Lee SH, Ikeda Y, Yamaguchi Y, Aze Y, et al. Dysregulation of TGF-beta1 receptor activation leads to abnormal lung development and emphysema-like phenotype in core fucose-deficient mice. Proc Natl Acad Sci U S A. 2005; 102:15791-15796. 
35. Shimada I, Shoji M, Futatsuya R, Katoh T, Kominato Y, Sakamoto $\mathrm{T}$ and Fujikura T. Elevation of ratio of urinary $\mathrm{N}$-acetylneuraminlactose to free sialic acid in some advanced cancer patients. J Gastroenterol. 1995; 30:21-27.

36. Jun L, Yuanshu W, Yanying X, Zhongfa X, Jian Y, Fengling W, Xianjun Q, Kokudo N, Wei T, Weixia Z and Shuxiang C. Altered mRNA expressions of sialyltransferases in human gastric cancer tissues. Med Oncol. 2012; 29:84-90.

37. Kodar K, Izotova J, Klaamas K, Sergeyev B, Jarvekulg $\mathrm{L}$ and Kurtenkov O. Aberrant glycosylation of the antiThomsen-Friedenreich glycotope immunoglobulin G in gastric cancer patients. World J gastroenterol. 2013; 19:3573-3582.

38. Song Y, Aglipay JA, Bernstein JD, Goswami S and Stanley P. The bisecting GlcNAc on N-glycans inhibits growth factor signaling and retards mammary tumor progression. Cancer Res. 2010; 70:3361-3371.

39. Tan ZQ, Lu W, Li X, Yang GL, Guo J, Yu HJ, Li Z and Guan F. Altered N-Glycan Expression Profile in Epithelialto-Mesenchymal Transition of NMuMG Cells Revealed by an Integrated Strategy Using Mass Spectrometry and Glycogene and Lectin Microarray Analysis. J Proteome Res. 2014; 13:2783-2795.

40. Yu H, Zhu M, Qin Y, Zhong Y, Yan H, Wang Q, Bian H and $\mathrm{Li} \mathrm{Z}$. Analysis of glycan-related genes expression and glycan profiles in mice with liver fibrosis. J Proteome Res. 2012; 11:5277-5285.

41. Yang G, Tan Z, Lu W, Guo J, Yu H, Yu J, Sun C, Qi X, Li $\mathrm{Z}$ and Guan F. Quantitative glycome analysis of N-glycan patterns in bladder cancer vs normal bladder cells using an integrated strategy. J Proteome Res. 2015; 14:639-653.
42. Gil GC, Iliff B, Cerny R, Velander WH and Van Cott KE. High throughput quantification of N-glycans using one-pot sialic acid modification and matrix assisted laser desorption ionization time-of-flight mass spectrometry. Anal Chem. 2010; 82:6613-6620.

43. YANG G-L, MA T-R and LI Z. Enrichment and Characterization of Total N-linked Glycans From Glycoproteins by Ultrafiltration Units and Mass Spectrometry. Prog Biochem Biophys. 2014; 41:403-408.

44. Yang G, Cui T, Wang Y, Sun S, Ma T, Wang T, Chen Q and $\mathrm{Li} \mathrm{Z}$. Selective isolation and analysis of glycoprotein fractions and their glycomes from hepatocellular carcinoma sera. Proteomics. 2013; 13:1481-1498.

45. Goetz JA, Novotny MV, Mechref Y. Enzymatic/chemical release of O-glycans allowing MS analysis at high sensitivity. Anal Chem. 2009; 81: 9546-9552.

46. Wang C, Fan W, Zhang P, Wang Z, Huang L. One-pot nonreductive O-glycan release and labeling with 1-phenyl3-methyl-5-pyrazolone followed by ESI-MS analysis. Proteomics. 2011; 11: 4229-4242.

47. Ceroni A, Maass K, Geyer H, Geyer R, Dell A and Haslam SM. GlycoWorkbench: a tool for the computer-assisted annotation of mass spectra of glycans. J Proteome Res. 2008; 7:1650-1659.

48. Hayek A, Beattie GM, Lopez AD and Chen P. The use of digital image processing to quantitate angiogenesis induced by basic fibroblast growth factor and transplanted pancreatic islets. Microvasc Res. 1991; 41:203-209.

49. Blatt RJ, Clark AN, Courtney J, Tully C and Tucker AL. Automated quantitative analysis of angiogenesis in the rat aorta model using Image-Pro Plus 4.1. Comput Methods Programs Biomed. 2004; 75:75-79. 